\section{Fruit Trait Variation in a Caribbean Germplasm Collection of Aromatic Hot Peppers (Capsicum chinense Jacq.)}

\author{
Sarah M. Bharath ${ }^{1}$ \\ Trinidad \& Tobago, West Indies \\ Christian Cilas \\ CIRAD, TA A106/02, 34398 Montpellier Cedex 5, France
}

Department of Life Sciences, Faculty of Science and Technology, The University of the West Indies, University Circular Road, St. Augustine,

\section{Pathmanathan Umaharan}

Department of Life Sciences, Faculty of Science and Technology, The University of the West Indies, University Circular Road, St. Augustine, Trinidad \& Tobago, West Indies

Additional index words. germplasm evaluation, morphological descriptors, conservation, fruit diversity, Trinidad \& Tobago

\begin{abstract}
Aromatic hot peppers (Capsicum chinense Jacq.) are an important agricultural commodity for many small-scale farmers in the Caribbean because it is a commercially viable crop and one that is integral to the cuisines of the region. The large variation in fruit shape, size, color, pungency, and aroma of this species facilitates a diverse range of uses. Using 264 accessions from a Caribbean germplasm collection (representing primarily the Caribbean Basin, Central and South America), this study investigated 1) morphological variation in 13 fruit descriptors of agro-economic importance; and 2) morphological groups based on geographic origin. All 13 fruit descriptors showed significant variation. Fruit color [immature (six states) and mature (12 states)] was the most diverse qualitative fruit trait. Among the quantitative traits, fruit weight and fruit width showed the highest broad-sense heritability $(0.81)$, and fruit weight was highly correlated with fruit width and placenta size. Cluster analysis revealed four main clusters, which did not show a clear separation of accessions based on major geographic regions, but there was a highly significant association $(P<0.0001)$ between geographic subgroups and the clusters to which they were assigned. Most accessions of the Northern Caribbean (particularly the Bahamas and Puerto Rico) separated quite distinctly from most accessions of the Southern Caribbean and clustered with most accessions of Central and South America. Accessions of the Southern Caribbean (Lesser Antilles, Trinidad \& Tobago) were substantially more similar to each other than they were to most accessions of Central and South America, thereby suggesting genetic differences between accessions of the Southern Caribbean islands and the mainland populations. Collectively, the results show that this germplasm collection contains useful accessions with desired fruit quality traits and a level of genetic variation that can be used to encourage its active conservation and use for further evaluation trials and crop improvement as well as guide ongoing complementary germplasm introductions to augment the collection's diversity.
\end{abstract}

In the Caribbean, three of the five domesticated Capsicum species are cultivated: $C$. annuum (sweet peppers), C. frutescens (bird peppers), and C. chinense (aromatic hot peppers). However, $C$. chinense is commercially the most important throughout the region (DeWitt and Bosland, 2009). South America is considered the center of origin and highest

Received for publication 24 Jan. 2013. Accepted for publication 11 Mar. 2013.

We thank the Department of Life Sciences for funding and facilitating this work. We also thank Julian Duncan and Thayil Sreenivasan for their critical reviews of the manuscript.

${ }^{1}$ To whom reprint requests should be addressed; e-mailsarahbharath@yahoo.com.
American mainland, new varieties have arisen displaying useful plant adaptations and desirable fruit traits. Recent molecular studies revealed the importance of the Caribbean as an important region of this species' diversification (Moses and Umaharan, 2012) as well as a region containing some of the most aromatic pungent peppers in the world (Bosland et al., 2012; Gibbs and O'Garro, 2004; Holder, 2008). As a known region of diversity for $C$. chinense, the Caribbean varieties could be potentially useful sources of variation in agronomically important traits, e.g., early flowering and fruiting, desired fruit quality traits, suitable plant growth habit, and disease resistance, among others.

The Caribbean is well known for its diverse range of pepper fruit forms and varied consumer preferences as a result of their varied cuisines. With the spread of Caribbean people and their cuisines to different parts of the world, aromatic hot peppers have fueled growing public interest in their cultivation for diverse commercial uses, e.g., the food industry (fresh consumption as a vegetable and processed products such as pepper mash, sauces, salsas, pickles, jams, and jellies), the defense industry (repellants, military use), pharmaceutical and health industries, and as ornamentals (Bosland and Votava, 2003; Cichewicz and Thorpe, 1996; DeWitt and Gerlach, 1990; Elkins, 1997; Jancsó et al., 1984; Lo et al., 2005). There has therefore been global increase in cultivation and parallel research and development to help meet the growing industry demands.

In the Caribbean, although many varieties exist, few are formally known and commercially exploited. Many others remain as unstabilized landraces showing inconsistent fruit quality traits and yield. Consequently, foreign hybrids, capable of higher yields and more consistent fruit quality, are rapidly replacing local varieties and this contributes to ongoing decline in diversity available to regional breeders. This decline, coupled with limited varieties currently available for use, also restricts the ability of the regional pepper industry to exploit development of diverse pepper products (Bharath, 2012). Systematic replacement of local varieties could facilitate complete loss of unique, valuable Caribbean germplasm and prevent diversification of the value-added pepper product industry in the region with possible considerable economic and social impact.

Jarret and Berke (2008) were the first to describe the morphological variation for fruit characteristics in an extensive USDA/ARS global $C$. chinense collection (330 accessions). However, only 14 accessions representing three Caribbean islands [Cuba (one), Puerto Rico (10), Trinidad (three)] were evaluated. The Caribbean Agricultural Research and Development Institute (CARDI) has also done some morphological characterization of regional varieties, but these were limited to eight to 10 landraces primarily from Trinidad, Guyana, and Barbados (CARDI, 2002). Most of the Caribbean's fruit diversity has therefore remained underrepresented in global and 
regional collections and consequently understudied and underdocumented even within the region itself (Bharath, 2012). There was therefore an urgent need to systematically document and characterize the region's current diversity and to place this diversity into regional context. This will serve as a necessary precursor to envisioned regional pepper breeding and improvement programs.

This present study investigated variation in fruit morphology in a Caribbean $C$. chinense germplasm collection held at The University

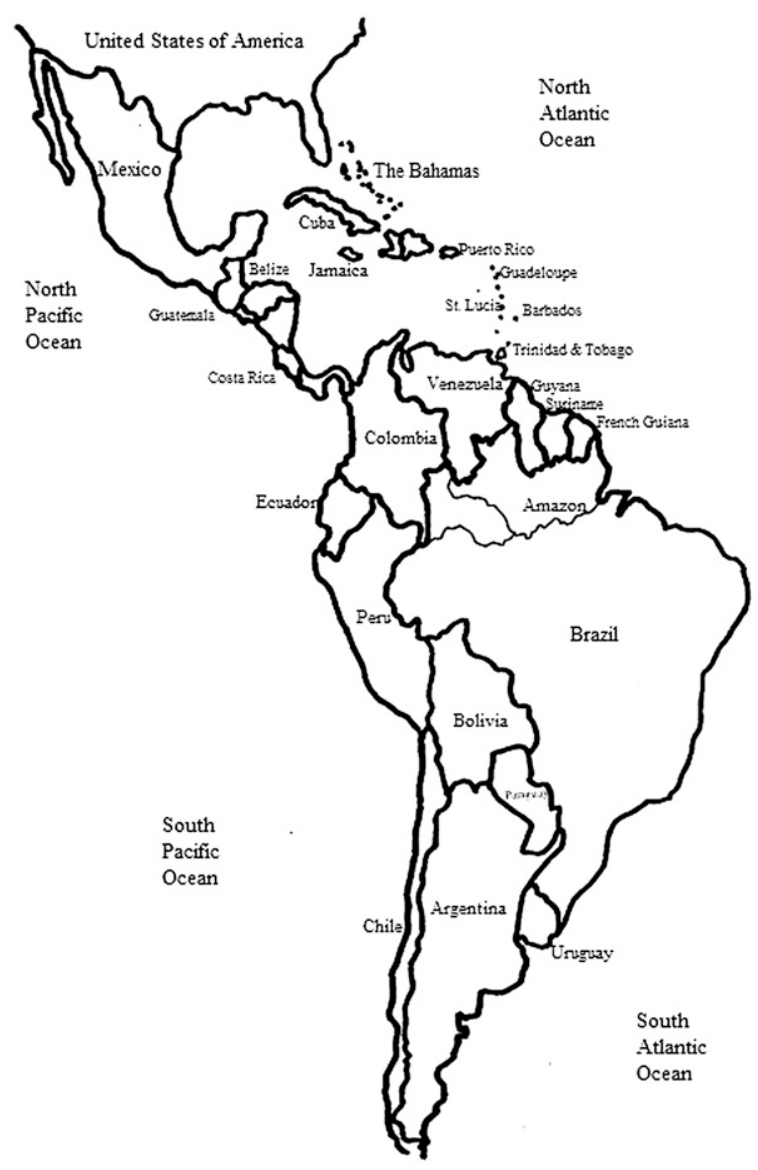

Fig. 1. Schematic map showing the geographic regions and subgroups used in this fruit morphology study.

of the West Indies, Trinidad (UWI). This germplasm represents material collected from three major regions of diversity: Central America, the Caribbean Basin (northern and southern territories), and South America with representatives from geographic subgroups (Fig. 2). Using the international Capsicum descriptor guide [International Plant Genetic Resources Institute et al. (IPGRI), 1995] to morphologically characterize the accessions, this study aimed to determine 1) the level of interaccession variation across 13 fruit descriptors; 2) any links between quantitative and qualitative fruit traits; and 3 ) the level of fruit morphological dissimilarity among accessions based on their geographic origins.

\section{Materials and Methods}

Germplasm. A total of 264 accessions were classed into eight geographic subgroups (Fig. 2): Central America, Greater Antilles/ Bahamas, Trinidad \& Tobago, Lesser Antilles, Guiana Shield, Lower Amazon, Upper Amazon, and other regions. The subgroup "other" included accessions from regions outside of the aforementioned seven subgroups as well as accessions whose country data were unknown. Before fruit data collection, each accession was confirmed as $C$. chinense using the combination of listed floral traits presented by Palloix and Bosland (European Cooperative for Plant Genetic Resources, 2008).

Experimentation. The seedlings were raised in trays containing a peat-moss mixture using standard nursery practices for hot peppers (Adams et al., 2007) and maintained at the UWI greenhouse. The seedlings were hardened when they were 4 weeks old and then transplanted into $20 \mathrm{~cm}$ diameter $\times 30 \mathrm{~cm}$ depth ultraviolet-resistant plastic pots containing a mixture of two parts top soil:one part sand:one part cured manure. The trial was

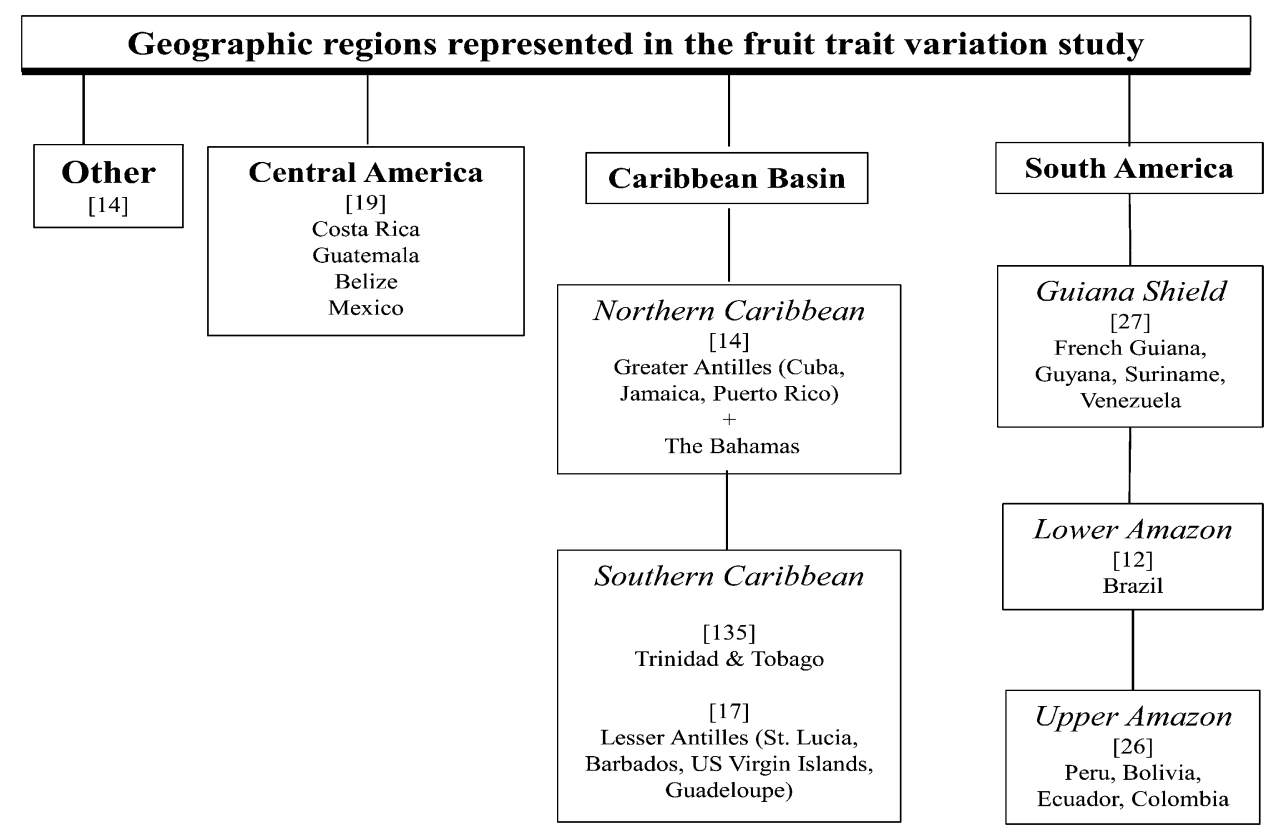

Fig. 2. Chart of the major geographic regions and subgroups represented in the study. Bracketed numbers indicate the number of accessions used per geographic zone. 
conducted at the university's field plot with the plants arranged in a randomized complete block design with three blocks and one plant per block per accession. Plants were irrigated once per day and kept weed-free (manually) throughout the experiment. Fertilizer applications and pest and disease control measures followed standard recommended practices for local hot pepper production (Adams et al., 2007).

Data collection. Thirteen fruits traits were scored (Table 1) and 10 randomly selected fruits were used per accession replicate for evaluation of each trait. The scoring classes provided by the IPGRI descriptor guide (IPGRI et al., 1995) were used for categorizing immature and mature fruit colors, fruit shape, pedicel persistence with fruit, and approximate placenta size. Fruit length, width, and pedicel length measures were taken using digital calipers (Tchibo, GmbH, Hamburg, Germany). Fruit weight measures were taken using a top pan balance (Thomas Scientific Model T410+, Swedesboro, NJ). All traits except immature fruit color were assessed at the fully mature, ripened stage. Fruit color was assessed using the Royal Horticultural Society's color chart. Pedicel persistence with fruit (pedicel remained firmly attached to the ripe fruit at harvest) was determined using the harvesting technique described by Motsenbocker (1996). Placenta size was determined relative to the fruit length: using a metric ruler, the placenta and fruit lengths were measured, the ratio calculated, and the number obtained was assigned to the IPGRI descriptor categories provided (Table 1). Four descriptors not present in the IPGRI list (fruit surface gloss, pericarp folding, presence of a tail, fruit surface pebbling) were included among the qualitative traits collected, because these features were consistently seen in some accessions of the collection. These four descriptors were assessed based on an in-house scoring method. Fruit surface gloss was evaluated under natural light and referred to the presence/absence of a very shiny fruit surface (Fig. 3A). Pericarp folding (best demonstrated in the Scotch Bonnet variety) refers to the convex folded form of the pericarp generally toward the distal end of the fruit (Fig. 3B). Descriptor states scored were absence/presence. The tail referred to the narrow elongation (whether slight or pronounced) of the distal end of the fruit (Fig. 3C) and was scored as either absent or present. Surface pebbling referred to points along the fruit surface where distinct, firm surface protrusions (varying sizes) were observed (Fig. 3D) and was scored based on absence/presence despite observed variation in number and distribution of this feature along the fruit. In addition to scoring this trait, preliminary anatomical evaluation was done to determine the physical nature of this feature. Using fresh pericarp material from five fruits of 1) smooth-surfaced and 2) pebbled fruits, thin sections were made, stained, and mounted according to the procedures outlined by Johansen (1940). The prepared slides were then examined using a light microscope (Olympus Optical Co. Ltd., Japan).

Table 1. Summary of the fruit descriptor traits assessed, states found, and their corresponding number of accessions successfully scored.

\begin{tabular}{|c|c|c|c|}
\hline & Descriptor trait & $\begin{array}{c}\text { Total accessions } \\
\text { successfully evaluated }^{z}\end{array}$ & $\begin{array}{c}\text { Descriptor states observed and corresponding } \\
\text { number of accessions }\end{array}$ \\
\hline 1 & Immature fruit color & 253 & White (5); yellow (2); green (243); purple (3) \\
\hline 2 & Mature fruit color & 252 & Yellow (40); orange $(38)$; red $(156)$; other $(18)$ \\
\hline 3 & Fruit shape & 257 & $\begin{array}{l}\text { Elongate (15); almost round (19); triangular (58); } \\
\text { campanulate (79); blocky (86) }\end{array}$ \\
\hline 4 & $\begin{array}{l}\text { Pedicel persistence } \\
\text { with fruit }\end{array}$ & 251 & Slight (16); intermediate (5); persistent (230) \\
\hline 5 & Placenta size & 204 & $\begin{array}{l}\text { Greater than one-fourth to half fruit length (125); } \\
\text { greater than half fruit length (79) }\end{array}$ \\
\hline 6 & Fruit gloss ${ }^{\mathrm{y}}$ & 248 & Absent (72); present (176) \\
\hline 7 & Surface pebbling ${ }^{\mathrm{y}}$ & 261 & Absent (249); present (12) \\
\hline 8 & Tail at distal end ${ }^{y}$ & 261 & Absent (243); present (18) \\
\hline 9 & Folded pericarp ${ }^{y}$ & 261 & Absent (171); present (90) \\
\hline 10 & Fruit length & 252 & $\begin{array}{l}\text { Long }(>47 \mathrm{~mm})(19) ; \text { intermediate } \\
\quad(>24<46 \mathrm{~mm})(202) ; \text { short }(<23 \mathrm{~mm})(31)\end{array}$ \\
\hline 11 & Fruit width & 252 & $\begin{array}{l}\text { Wide }(27-40 \mathrm{~mm})(143) \text {; intermediate } \\
\quad(14-26 \mathrm{~mm})(88) \text {; narrow }(<14 \mathrm{~mm})(21)\end{array}$ \\
\hline 12 & Pedicel length & 252 & $\begin{array}{l}\text { Long }(>37 \mathrm{~mm})(7) \text {; intermediate } \\
\qquad(26>\times<36 \mathrm{~mm})(181) ; \text { ahort }(<26 \mathrm{~mm})(64)\end{array}$ \\
\hline 13 & Fruit weight & 241 & $\begin{array}{l}\text { Heavy }(>10 \mathrm{~g})(18) \text {; intermediate }(5-9 \mathrm{~g})(119) \\
\quad \text { light }(<5 \mathrm{~g})(104)\end{array}$ \\
\hline
\end{tabular}

${ }^{\mathrm{z} A c c e s s i o n}$ totals vary for different traits due to loss of fruit before collection or absence of suitable fruit material at the time of scoring.

${ }^{y}$ Descriptor traits not included in the IPGRI Capsicum descriptor guide (IPGRI et al., 1995).

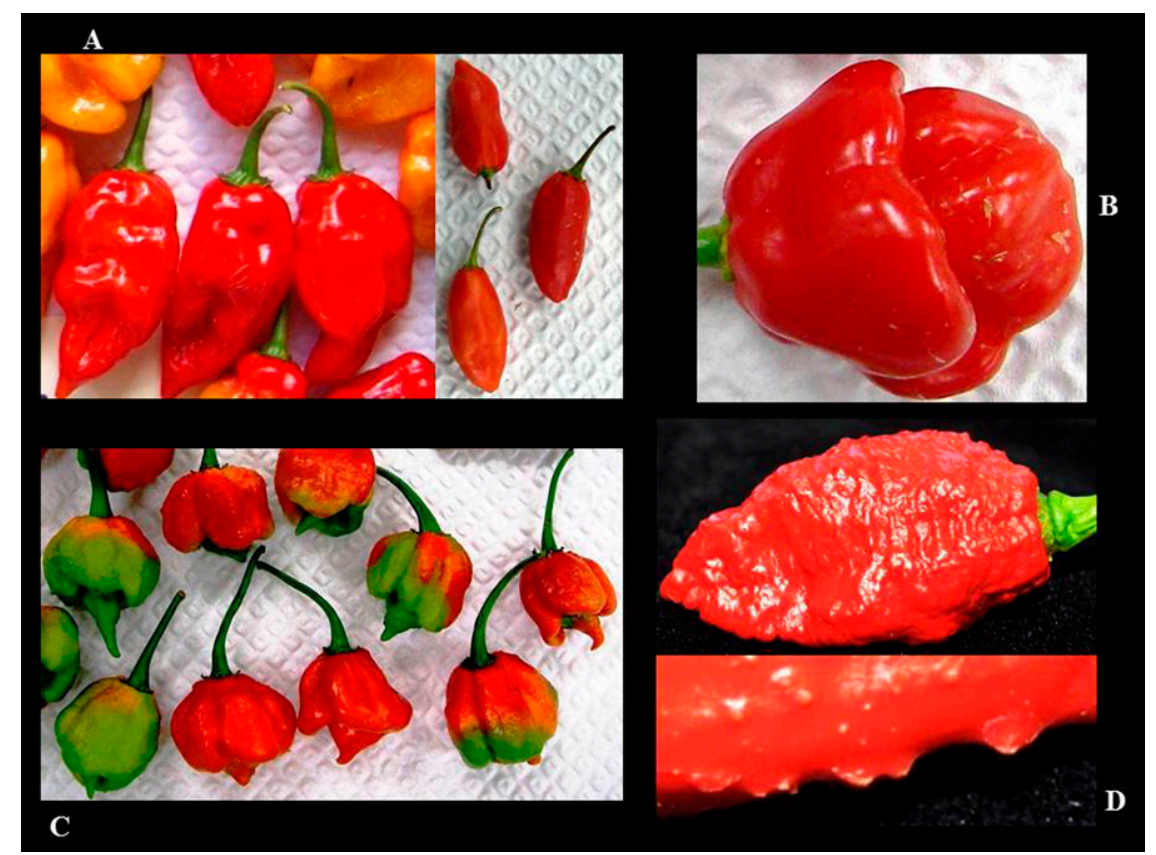

Fig. 3. The four descriptors included in the 13 fruit traits evaluated. (A) Fruit gloss present (left) and absent (right). (B) Pericarp fold. (C) Tail at distal end of fruit. (D) Surface pebbling [entire fruit (top), close-up (bottom)].

Data analysis. All 13 traits were evaluated at three levels: 1) accession; 2) geographic subgroups (eight); and 3) major geographic regions of which there were three: Central America/Northern Caribbean, Southern Caribbean, and South America (Fig. 1). As a result of unavoidable circumstances with fruit material of some accessions (predominantly Trinidad \& Tobago accessions), not all 264 accessions could be scored completely for each trait. This necessarily reduced the possibility of a thorough analysis of individual accessions across all 13 descriptors. However, for all geographic regions and subgroups used in the study, the populations evaluated remained well represented. The data collected and analyzed therefore still provided useful insight into the variation and morphological structure of the collection.

Qualitative trait data were summarized to provide frequencies per class of trait and $\chi^{2}$ analyses performed to assess relationships between traits and geographic origin using XLSTAT 2008.08.03 (Addinsoft, USA). Quantitative trait data were evaluated using analysis of variance to determine the level of variation among the accessions. Broad-sense heritability values along with the associated 
confidence intervals were also estimated for these quantitative traits using the Wald method (Agresti and Coull, 1998). Estimations of heritabilities were given by the ratios of genetic variances, i.e., " variety » variances and phenotypic variances:

$$
H_{b}^{2}=\frac{\sigma_{G}^{2}}{\sigma_{P}^{2}}=\frac{\sigma_{v}^{2}}{\sigma_{v}^{2}+\sigma_{e}^{2}}
$$

where $H_{b}^{2}=$ broad-sense heritability, $\sigma_{G}^{2}$ and $\sigma_{P}^{2}$ are, respectively, genetic and phenotypic variances, and $\sigma_{v}^{2}$ and $\sigma_{e}^{2}$ are, respectively, variety and error variances.

Genetic correlations were then estimated between the quantitative traits. The random model was applied for multivariate analysis, allowing for an estimation of genetic covariances and correlations between these traits (Hill, 1971). Variance analysis was used to determine any links between fruit weight (as a variable) and the qualitative traits (as factors). These data analyses were done using SAS 9.1 (SAS Institute Inc., Cary, NC).

Agglomerative hierarchical clustering (Ward's method) was used to determine the dissimilarity among the accessions (using XLSTAT 2008.08.03). As a result of missing data points for different accessions across different traits, and a need to retain the largest number of accessions for the cluster analysis, only three fruit traits (weight, shape, and mature color) were used. These three traits were selected based on their primary importance for consumers and allowed the successful analysis of 234 accessions $(\approx 89 \%$ of the original total) with all eight geographic subgroups represented.

\section{Results}

\section{Qualitative traits}

Fruit color. Four main immature fruit colors were found in the collection (Table 1): white, yellow, green (three categories), and purple. Green-colored fruit was most common [light green (102 accessions); green (132 accessions); dark green (nine accessions)]. Across the major geographic regions (Table 2), South America (specifically the Upper Amazon) contained the largest range of color states (six), exceeding Central America/Northern Caribbean (five states) and the Southern $\mathrm{Ca}$ ribbean (four states). Twelve mature color states were found in the collection, but red fruits were most common [light red (15 accessions); red (72 accessions); dark red (69 accessions)] (Table 1). South America contained the largest number of color states (12) and exceeded the 10 states found in the
Southern Caribbean and the nine states of Central America/Northern Caribbean (Table 2).

Fruit shape. Five descriptor states were observed: blocky fruit was most common by a small margin (86 accessions) followed by campanulate fruit (79 accessions). South America displayed the lowest range of states (four) and was exceeded by the Southern Caribbean and Central America/Northern Caribbean (both displayed five states).

Pedicel persistence with the fruit. Persistent pedicels (firmly attached to the fruit at harvest) were most common throughout the collection (230 accessions) but all regions contained several accessions with less persistent pedicels. South American accessions (specifically the Upper Amazon) displayed all three degrees of persistence as did the Southern Caribbean accessions, whereas Central America/Northern Caribbean contained accessions with only two states; the pedicels were either easy to remove or they were firmly attached to the fruit at harvest.

Placenta size. All geographic regions contained accessions displaying the two states found in the collection; however, fruit types containing smaller placentas (i.e., onefourth to half fruit length) were more common than types with placentas greater than half the fruit length (125 vs. 79 accessions).

Table 2. Descriptor state frequencies ${ }^{\mathrm{z}}$ observed per trait according to geographic region and geographic subgroup.

\begin{tabular}{|c|c|c|c|c|c|c|c|c|c|}
\hline \multirow[b]{2}{*}{ Descriptor trait } & \multirow[b]{2}{*}{ Descriptor states } & \multicolumn{2}{|c|}{ Central America/Northern Caribbean } & \multicolumn{2}{|c|}{ Southern Caribbean } & \multicolumn{3}{|c|}{ South America } & \multirow{2}{*}{$\begin{array}{c}\text { Othe } \\
\text { OR }\end{array}$} \\
\hline & & $\mathrm{CA}$ & GAB & TT & LeA & GS & LA & UA & \\
\hline \multirow[t]{6}{*}{ Immature color } & White & 0 & 1 & 1 & 0 & 1 & 1 & 1 & 0 \\
\hline & Yellow & 1 & 0 & 0 & 0 & 0 & 0 & 1 & 0 \\
\hline & Light green & 5 & 6 & 55 & 8 & 11 & 7 & 11 & 3 \\
\hline & Green & 11 & 6 & 75 & 7 & 13 & 4 & 11 & 6 \\
\hline & Dark green & 2 & 0 & 4 & 0 & 1 & 0 & 8 & 1 \\
\hline & Dark purple & 0 & 0 & 0 & 0 & 0 & 0 & 1 & 2 \\
\hline \multirow[t]{12}{*}{ Mature color } & Lemon yellow & 1 & 0 & 4 & 1 & 3 & 1 & 4 & 0 \\
\hline & Dark yellow & 1 & 1 & 19 & 0 & 1 & 1 & 0 & 3 \\
\hline & Orange-yellow & 0 & 1 & 15 & 0 & 2 & 1 & 1 & 0 \\
\hline & Light (pale) orange & 0 & 0 & 3 & 0 & 2 & 1 & 0 & 0 \\
\hline & Orange & 0 & 1 & 4 & 0 & 1 & 0 & 5 & 1 \\
\hline & Light red & 2 & 0 & 8 & 1 & 1 & 0 & 2 & 1 \\
\hline & Red & 7 & 7 & 40 & 4 & 4 & 3 & 7 & 0 \\
\hline & Dark red & 7 & 2 & 30 & 7 & 9 & 4 & 6 & 4 \\
\hline & Brown & 0 & 0 & 5 & 2 & 1 & 0 & 1 & 1 \\
\hline & Black & 0 & 0 & 0 & 0 & 0 & 0 & 0 & 1 \\
\hline & Ivory & 1 & 0 & 0 & 0 & 1 & 1 & 0 & 0 \\
\hline & Salmon & 0 & 1 & 1 & 0 & 1 & 0 & 0 & 1 \\
\hline \multirow[t]{5}{*}{ Whole shape } & Elongate & 2 & 5 & 5 & 1 & 0 & 0 & 0 & 2 \\
\hline & Almost round & 2 & 1 & 3 & 0 & 8 & 2 & 3 & 0 \\
\hline & Triangular & 11 & 3 & 20 & 5 & 6 & 3 & 9 & 1 \\
\hline & Campanulate & 3 & 4 & 47 & 7 & 4 & 4 & 7 & 3 \\
\hline & Blocky & 1 & 0 & 50 & 2 & 9 & 2 & 6 & 6 \\
\hline \multirow[t]{3}{*}{ Pedicel persistence } & Slight & 1 & 5 & 3 & 1 & 0 & 1 & 1 & 1 \\
\hline & Intermediate & 0 & 0 & 4 & 0 & 0 & 0 & 0 & 1 \\
\hline & Persistent & 15 & 8 & 121 & 15 & 26 & 11 & 24 & 10 \\
\hline \multirow[t]{2}{*}{ Placenta size } & One-fourth to half fruit length & 5 & 5 & 69 & 13 & 9 & 5 & 9 & 10 \\
\hline & Greater than half fruit length & 11 & 3 & 35 & 3 & 14 & 2 & 9 & 2 \\
\hline \multirow[t]{2}{*}{ Fruit gloss } & Absent & 8 & 7 & 29 & 1 & 8 & 4 & 9 & 6 \\
\hline & Present & 11 & 6 & 97 & 14 & 18 & 8 & 16 & 6 \\
\hline \multirow[t]{2}{*}{ Pericarp fold } & Absent & 16 & 10 & 74 & 8 & 22 & 9 & 23 & 9 \\
\hline & Present & 3 & 3 & 60 & 8 & 5 & 3 & 3 & 5 \\
\hline \multirow[t]{2}{*}{ Tail } & Absent & 18 & 13 & 121 & 15 & 26 & 11 & 25 & 14 \\
\hline & Present & 1 & 0 & 13 & 1 & 1 & 1 & 1 & 0 \\
\hline \multirow[t]{2}{*}{ Pebbling } & Absent & 0 & 13 & 125 & 15 & 26 & 12 & 26 & 13 \\
\hline & Present & 0 & 0 & 9 & 1 & 1 & 0 & 0 & 1 \\
\hline
\end{tabular}

${ }^{\mathrm{z}}$ Accession totals vary for different traits as a result of loss of fruit before collection or absence of suitable fruit material at the time of scoring.

$\mathrm{CA}=$ Central America; GAB = Greater Antilles/Bahamas; GS = Guiana Shield; LeA = Lesser Antilles; LA = Lower Amazon; OR = other regions; TT = Trinidad \& Tobago; UA = Upper Amazon. 
Fruit gloss, pericarp fold, and tail. Glossy fruit was more common than non-glossy fruit in this collection (176 vs. 72 accessions), but both states were displayed across all regions. The pericarp fold ( 80 accessions) and the tail (18 accessions) were not dominant features in the collection but were still found in accessions of the three major regions studied and were notably most frequent in the Southern Caribbean.

Surface pebbling. This trait was found only in 12 accessions of the collection [derived from the Southern Caribbean and South America (specifically the Guiana Shield region)]. Preliminary analysis of the surface pebbling showed that sections of smoothsurfaced fruit displayed no epidermal pebbling even in the cross-section (Fig. 4A), whereas fruit with a pebbled epidermis revealed lignified cells and increased suberin levels immediately at the pebbled zones (red-stained regions). Notably, larger pebbled areas displayed considerable cell wall lignification and suberized zones (Fig. 4B-D).

\section{Quantitative traits}

Distributions of all four quantitative traits were normal and analysis of variance showed significant differences $(P<0.0001)$ among accessions for each trait measured (Tables 3 and 4; Fig. 5). The highest estimated heritability values were found for fruit weight and fruit width (0.810 and 0.807 , respectively). The collection contains predominantly light to intermediate weight fruits of intermediate fruit length and wide fruit widths with intermediate length pedicels. The Southern Caribbean accessions displayed highest average values for fruit length, width, and weight (Fig. 5), whereas the highest average pedicel length was found in the Northern Caribbean accessions. However, the variances for each of these four traits in the Southern Caribbean accessions (particularly Trinidad \& Tobago) were always the lowest of all regions represented (Table 4; Fig. 5). Conversely, South America and Central America/Northern Caribbean (despite their substantially smaller number of accessions) displayed much higher variances in these four quantitative traits. Notably, the variances found in the South American accessions exceeded those of Central America/Northern Caribbean in all the quantitative traits except fruit weight.

\section{Correlation analysis of the quantitative traits}

The correlation matrix (data not shown) revealed a moderate significant positive association between pedicel length and fruit length $(r=0.54 ; P<0.05)$, fruit length, and fruit weight $(r=0.53 ; P<0.05)$ and between pedicel length and fruit weight $(r=0.48 ; P<$ $0.05)$. The largest correlation coefficient was found between fruit width and fruit weight $(r=0.80 ; P<0.05)$.

\section{Qualitative and quantitative trait interactions}

No significant link was found between fruit weight and fruit gloss $(P=0.23)$.

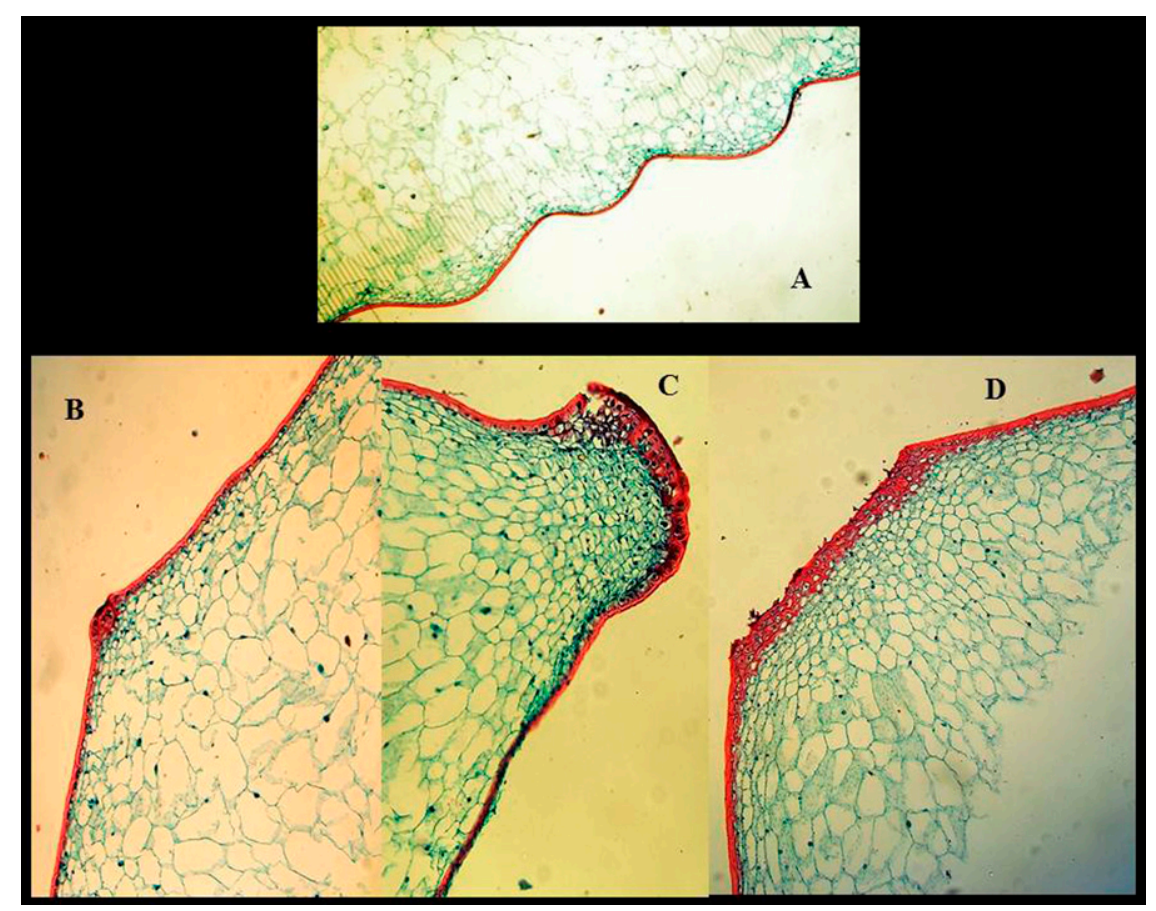

Fig. 4. Vertical section through (A) smooth pericarp, (B) small pebbled area, and (C-D) very large pebbled areas.

Table 3. Summary data for the four quantitative traits evaluated in the accessions of the University of West Indies $C$. chinense germplasm collection.

\begin{tabular}{|c|c|c|c|c|}
\hline & $\begin{array}{l}\text { Fruit length } \\
\quad(\mathrm{mm})\end{array}$ & $\begin{array}{l}\text { Fruit width } \\
(\mathrm{mm})\end{array}$ & $\begin{array}{l}\text { Pedicel length } \\
(\mathrm{mm})\end{array}$ & Fruit wt (g) \\
\hline $\begin{array}{l}\text { Total number of accessions } \\
\text { successfully evaluated }\end{array}$ & 252 & 252 & 252 & 241 \\
\hline Maximum & 70.44 & 40.32 & 44.84 & 14.50 \\
\hline Minimum & 6.27 & 6.83 & 14.75 & 0.20 \\
\hline Average & 35.29 & 26.67 & 27.70 & 5.68 \\
\hline Standard deviation & 9.97 & 8.09 & 4.55 & 2.83 \\
\hline Broad-sense heritability & 0.7338 & 0.8068 & 0.5198 & 0.8103 \\
\hline Confidence interval & $0.6838-0.7839$ & $0.7683-0.8452$ & $0.4427-0.5969$ & $0.7746-0.8461$ \\
\hline
\end{tabular}

${ }^{2}$ Accession totals vary for different traits as a result of loss of fruit before collection or absence of suitable fruit material at the time of scoring.

Table 4. Average values by geographic subgroup for the four quantitative traits evaluated in the University of West Indies C. chinense germplasm collection. ${ }^{2}$

\begin{tabular}{lcccccccc}
\hline $\begin{array}{l}\text { Geographic } \\
\text { subgroup }\end{array}$ & $\begin{array}{c}\text { Avg fruit } \\
\text { length }(\mathrm{mm})\end{array}$ & \multicolumn{1}{c}{ SD } & $\begin{array}{c}\text { Avg fruit } \\
\text { width }(\mathrm{mm})\end{array}$ & $\begin{array}{c}\text { SD } \\
\text { CA }\end{array}$ & $\begin{array}{c}\text { Avg pedicel } \\
\text { length }(\mathrm{mm})\end{array}$ & SD. & $\begin{array}{c}\text { Avg fruit } \\
\text { wt }(\mathrm{g})\end{array}$ & SD \\
CA & 31.59 & 9.23 & 20.95 & 7.99 & 26.29 & 4.89 & 3.61 & 1.07 \\
GAB & 30.86 & 9.22 & 21.14 & 9.12 & 29.46 & 4.93 & 3.01 & 2.09 \\
TT & 37.21 & 6.96 & 30.28 & 5.89 & 28.49 & 3.61 & 6.73 & 0.39 \\
LeA & 38.32 & 9.82 & 29.31 & 6.74 & 28.75 & 3.60 & 6.85 & 2.82 \\
GS & 32.47 & 14.17 & 22.91 & 8.68 & 25.55 & 5.13 & 4.64 & 0.53 \\
LA & 26.87 & 10.98 & 19.08 & 8.74 & 24.36 & 5.05 & 3.43 & 0.51 \\
UA & 35.64 & 15.25 & 21.51 & 6.82 & 27.08 & 6.20 & 4.80 & 0.64 \\
OR & 35.86 & 7.39 & 26.96 & 7.98 & 27.51 & 5.02 & 5.50 & 1.01
\end{tabular}

${ }^{2}$ Total number of accessions assessed for fruit length, width, and pedicel length: CA (19); GAB (14); TT (128); LeA (15); GS (26); LA (12); UA (25); OR (13). Total number of accessions assessed for fruit weight: CA (18); GAB (13); TT (123); LeA (15); GS (24); LA (12); UA (22); OR (14).

$\mathrm{CA}=$ Central America; GAB = Greater Antilles/Bahamas; TT = Trinidad \& Tobago; LeA = Lesser Antilles; GS = Guiana Shield; LA = Lower Amazon; UA = Upper Amazon; OR = other regions

However, highly significant links $(P<0.0001)$ existed between fruit weight and 1) immature fruit color $(\mathrm{F}=4.78) ; 2)$ mature color $(\mathrm{F}=5.39)$; 3) fruit shape $(\mathrm{F}=29.17)$; and 4) pericarp folding $(\mathrm{F}=31.70)$ with the largest magnitude of interaction found with 5) placenta size $(F=61.32)$.

\section{Cluster analysis}

Dissimilarity analysis produced four main clusters (Fig. 6) with no immediately distinct separation of accessions based on major geographic region, because all clusters contained accessions from most regions (Table 5). However, analysis at the level of geographic 

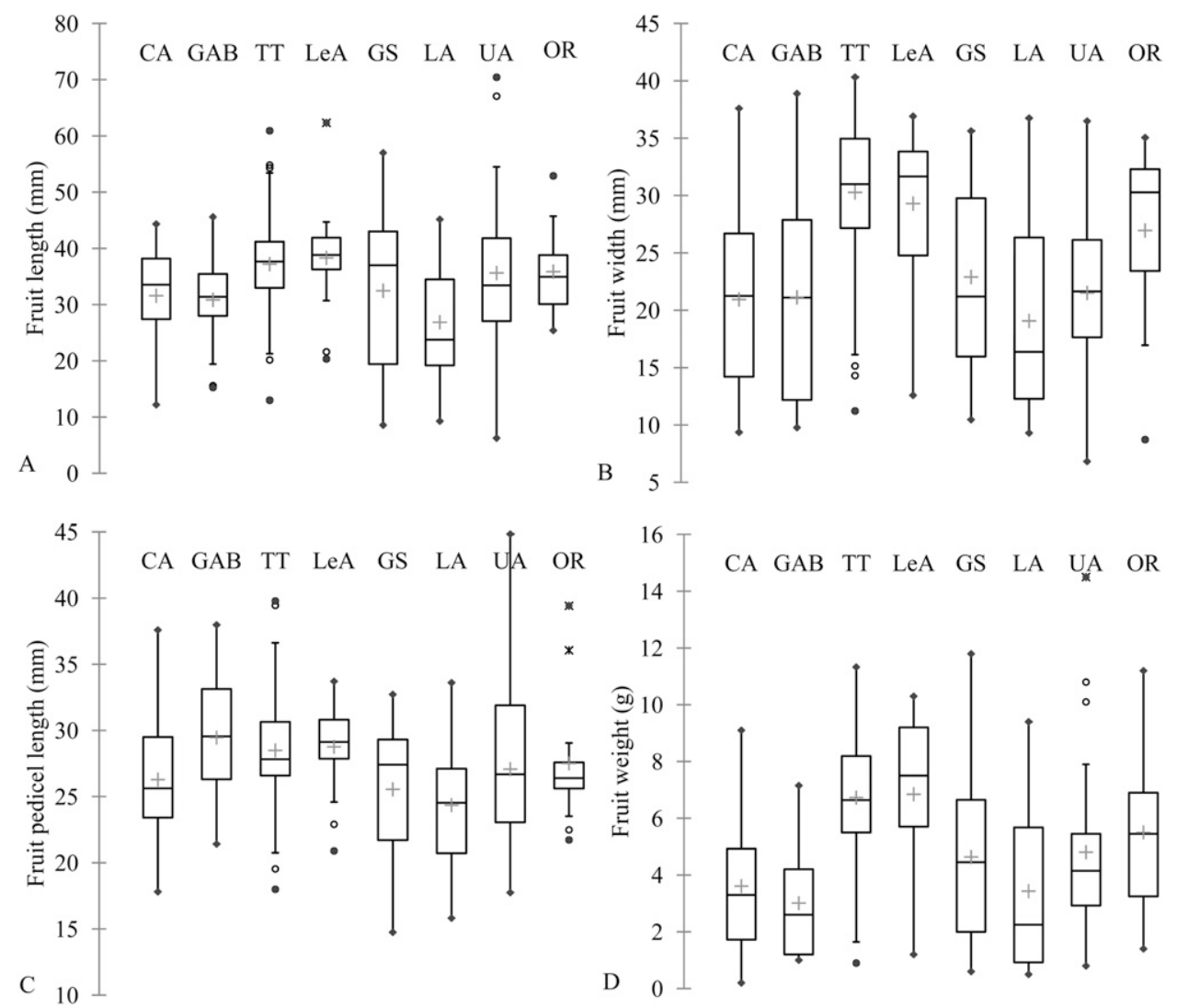

Fig. 5. Box plots showing variation across geographical subgroups for $(\mathbf{A})$ fruit length, $(\mathbf{B})$ fruit width, $(\mathbf{C})$ fruit pedicel length, and $(\mathbf{D})$ fruit weight. $C A=$ Central America; $\mathrm{GAB}=$ Greater Antilles/the Bahamas; TT = Trinidad \& Tobago; LeA = Lesser Antilles; GS = Guiana Shield; LA = Lower Amazon; UA = Upper Amazon; OR $=$ Other regions.

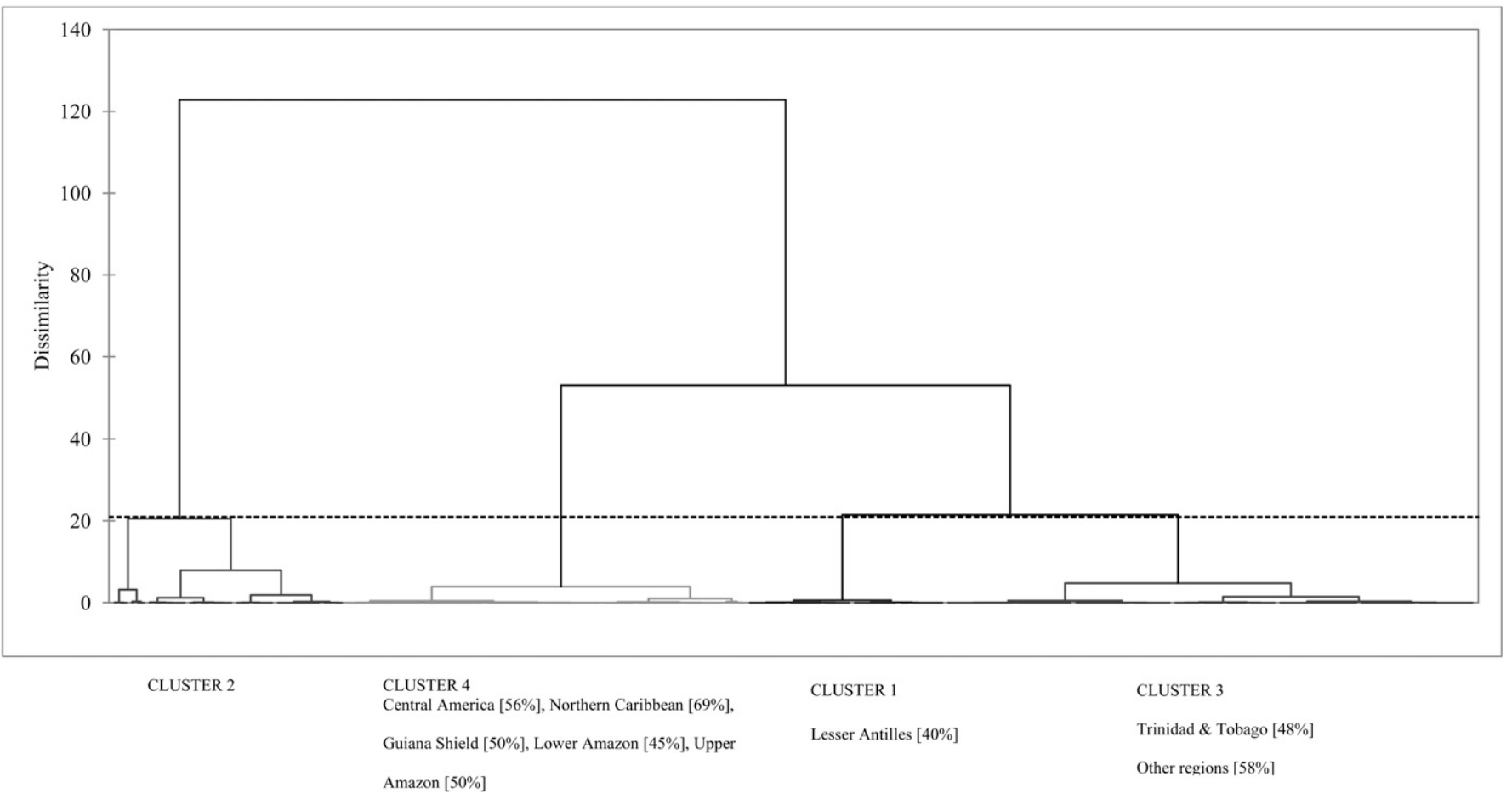

Fig. 6. Cluster analysis of a subset of the $C$. chinense accessions (234) using three fruit descriptors. Geographic regions listed beneath Clusters 1,3 , and 4 highlight the partitioning of geographic subgroups into these particular clusters. Table 5 provides the complete list for each cluster.

subgroup revealed a significant link $(\mathrm{df}=21$; $\left.\chi^{2}=32.671 ; P<0.0001 ; \alpha=0.05\right)$ between accession distribution and the clusters to which they were assigned.
Cluster 1 (containing marginally most accessions from the Lesser Antilles) and Cluster 3 (containing most accessions of Trinidad \& Tobago, other regions) were more closely related to each other than they were to Clusters 2 and 4 . Cluster 4 contained most of the accessions of Central America, the Northern Caribbean (notably represented only by 
Table 5. The total number of accessions used per geographic subgroup in the cluster analysis and the percent distribution across the four clusters.

\begin{tabular}{|c|c|c|c|c|c|c|c|}
\hline \multirow[b]{2}{*}{ Major geographic region } & \multirow[b]{2}{*}{ Geographic subgroups } & \multirow{2}{*}{$\begin{array}{l}\text { Original number of } \\
\text { accessions used in the study }\end{array}$} & \multirow{2}{*}{$\begin{array}{l}\text { Number of accessions } \\
\text { retained for cluster analysis }\end{array}$} & \multicolumn{4}{|c|}{ Percentage distribution across clusters } \\
\hline & & & & 1 & 2 & 3 & 4 \\
\hline \multirow{2}{*}{$\begin{array}{l}\text { Central America/Northern } \\
\text { Caribbean }\end{array}$} & Central America & 19 & 18 & 6 & 6 & 33 & $56^{\mathbf{z}}$ \\
\hline & Greater Antilles/Bahamas & 14 & 13 & 0 & 8 & 23 & 69 \\
\hline \multirow[t]{2}{*}{ Southern Caribbean } & Lesser Antilles & 17 & 15 & 40 & 13 & 33 & 13 \\
\hline & Trinidad \& Tobago & 135 & 119 & 17 & 22 & 48 & 13 \\
\hline \multirow[t]{3}{*}{ South America } & Guiana Shield & 27 & 24 & 8 & 17 & 25 & 50 \\
\hline & Lower Amazon & 12 & 11 & 18 & 18 & 18 & 45 \\
\hline & Upper Amazon & 26 & 22 & 9 & 18 & 23 & 50 \\
\hline \multirow[t]{2}{*}{ Other } & Other & 14 & 12 & 8 & 0 & 58 & 33 \\
\hline & Total & 264 & 234 & & & & \\
\hline
\end{tabular}

${ }^{\mathrm{z} B o l d e d ~ n u m b e r s ~ i n d i c a t e ~ t h e ~ c l u s t e r ~ c o n t a i n i n g ~ t h e ~ l a r g e s t ~ p e r c e n t a g e ~ o f ~ a c c e s s i o n s ~ f r o m ~ t h e ~ c o r r e s p o n d i n g ~ g e o g r a p h i c ~ s u b g r o u p . ~}$

accessions from the Bahamas and Puerto Rico), Guiana Shield, and both Amazon regions. Cluster 2 was most different from the other three clusters and contained a small number of accessions from every region except the Greater Antilles. Ranking of the clusters for average fruit weight revealed in descending order: Cluster $1>$ Cluster $2>$ Cluster $3>$ Cluster 4 . Regarding fruit shape and color, Cluster 1 contained campanulate red fruit, Cluster 2 contained campanulate orange-yellow fruit, Cluster 3 contained campanulate dark red fruit, and Cluster 4 contained triangular red fruit.

\section{Discussion}

Our findings indicate that there is significant and potentially unique fruit trait variation in this germplasm collection. The high broadsense heritabilities and strong significant correlation between fruit width and weight make these two traits suitable for improvement through breeding. In the accessions of the Southern Caribbean, the low variances in fruit weight, width, length, and pedicel length (despite higher numbers of accessions compared with the other two major regions) suggest considerable preferential selection for these traits in the Southern Caribbean. This possibly indicates higher production and consumption of fruits with these traits as well as a systematic narrowing of the genetic variation in these Southern Caribbean varieties. Not surprisingly, the mega-centers of diversity (Central and South America) together presented the highest variances in these four quantitative fruit traits. This lends support to the findings that main centers of origin and diversity tend to display high trait variation and this variation decreases as there is movement away from the mainland (Frankham et al., 2002).

Although dissimilarity analysis of the accessions did not show clear separation of any major geographic region (Table 5), there is still some indication of morphological clustering based on geographic subgroups within the four clusters. This observation was also made in the molecular diversity analysis (Moses and Umaharan, 2012). Most Southern Caribbean accessions (65\%) are morphologically quite similar to each other, as seen by the proximity of Clusters 1 and 3. However, these Southern Caribbean accessions were far less similar to most Central and South American accessions and those of the Northern Caribbean (particularly the Bahamas and Puerto Rico) found in Cluster 4 (Fig. 6). This suggests underlying genetic differences between certain accessions of the Southern Caribbean and the other geographic regions. The similarity of variances between accessions of the Northern Caribbean and Central America, coupled with the clustering of most of their accessions in Cluster 4, suggests underlying genetic similarity resulting from possible introduction of types into the Northern Caribbean (especially the Bahamas and Puerto Rico) from the Central American regions.

These fruit morphological studies suggest that the Southern Caribbean subpopulation (Lesser Antilles/Trinidad \& Tobago) of Clusters 1 and 3 could have formed as a result of 1 ) strong historical and geographical isolation from the South American mainland population as well as 2) active selection for larger, heavier fruit. The genetic data (Moses and Umaharan, 2012) revealed that the Guiana Shield group contained accessions that fell into both the Upper and Lower Amazon groups. This finding is supported by our morphological study because these Guiana Shield accessions are included in Cluster 4 together with the majority of Lower and Upper Amazon accessions. Unlike the molecular findings, however, the Northern Caribbean accessions (specifically from the Bahamas and Puerto Rico) could not be morphologically distinguished from the Central and South American groups. Strong physical similarities therefore exist among the populations of this collection, but the underlying genetic variability gives us an opportunity to exploit this variation for breeding and subsequent commercial use.

The four additional traits scored in this study provided a unique opportunity to highlight accessions with traits not generally consciously sought after by (especially Caribbean) consumers but influential nonetheless in their choice of peppers for consumption. Fruit gloss serves primarily an aesthetic role in peppers because it is associated with fruit freshness and visual appeal, which are important first impressions for consumers. The intensity of gloss is a function of wax chemical composition and wax serves an important physiological role in the fruit regarding water loss and surface permeability (Kolatukuddy, 1984; Lownds et al., 1993; Mintz-Oron et al., 2008). The significant link between folded pericarp and fruit weight may have possible implications for breeders and producers. The folded pericarp is a standard identifier of the Scotch Bonnet variety and its occurrence in other varieties has sometimes created identity confusion for consumers and misuse by vendors seeking a higher price (personal observation). The tail feature (unknown origin) is now a signature trait of the world-famous Trinidad Butch T Scorpion and Trinidad Moruga Scorpion pepper varieties. If it is indeed unique to the Scorpion varieties, it may provide a means of rapid field identification. The pebbled fruit surface, generally unattractive to many consumers, is locally considered (i.e., Trinidad) as a sign of high fruit pungency and is interestingly always found on fruit surfaces of extremely pungent landraces (e.g., the Scorpion, Congo, Seven Pot) of Trinidad (personal observations). It is also strikingly demonstrated on the fruits of the Bhut Jolokia (personal observations). The anatomical studies revealed that these pebbled areas demonstrate features typical of a plant's wounding response (Rittinger et al., 1987; Walter et al., 1990). Pest or insect attacks have not been considered plausible explanations for these wounded areas because routine crop management greatly reduced their populations. These pebbled zones may therefore indicate an event intrinsic to the pungent fruits themselves. We currently hypothesize that the prominent cell wall lignification displayed (Fig. 4) may be analogous to the blistering seen on the epidermis of the placenta resulting from accumulation of the capsaicinoids just beneath the epidermal surface (Stewart et al., 2007). Further work is required to fully explain the origin of this feature. Demonstration of a link between high pungency and surface pebbling could provide an invaluable means of rapid field identification of very pungent varieties.

Despite gaps in the data set (primarily for some accessions of Trinidad \& Tobago), we were still able to adequately represent the major geographic regions and their subgroups and evaluate the overall value of the accessions in this collection. This fruit descriptor study has documented a significant and interesting range of variation across several fruit quality traits and has allowed us to compile a working database for these accessions. This database now provides useful reference information for 1) possible immediate use of select accessions for commercial purposes (fresh market, fresh fruit processing, dried 
spice market, oleoresin extraction, ornamental plants); and for 2) identification of parent material for variety improvement and other breeding studies. We have also demonstrated possible key underlying genetic differences among accessions of the three major regions of diversity: Central America, the Caribbean Basin, and South America. This provides justification for continued conservation and more in-depth evaluation of the accessions in the collection. It also highlights the need to maintain a broad genetic base in the Southern Caribbean accessions to facilitate diverse industry needs. Use of this morphological information together with the existing genetic diversity data (Moses and Umaharan, 2012) is expected to contribute to future decisions concerning use of these germplasm resources as well as guide future germplasm introductions that will complement the existing genetic diversity of this collection.

\section{Literature Cited}

Adams, H., P. Umaharan, R. Brathwaite, and K. Mohammed. 2007. Hot pepper production manual for Trinidad and Tobago. The Caribbean Agricultural Research and Development Institute, St. Augustine, Trinidad and Tobago.

Agresti, A. and B.A. Coull. 1998. Approximate is better than 'exact' for interval estimation of binomial proportions. Amer. Stat. 52:119-126.

Bharath, S.M. 2012. Morphological characterisation of a caribbean germplasm collection of Capsicum chinense Jacq. MPhil thesis, The University of the West Indies, Trinidad \& Tobago.

Bosland, P.W., D. Coon, and G. Reeves. 2012. 'Trinidad Moruga Scorpion' pepper is the world's hottest measured chile pepper at more than two million Scoville heat units. HortTechnology 22:534-538.

Bosland, P.W. and E.J. Votava. 2003. Peppers: Vegetable and spice Capsicums. Crop Production Science in Horticulture 12. CAB International Publishing, Wallingford, UK.

Caribbean Agricultural Research and Development Institute. 2002. Hot pepper: Hot pepper (Capsicum chinense Jacq.). The University of the West Indies, St. Augustine, Trinidad and Tobago.

Cichewicz, R.H. and P.A. Thorpe. 1996. The antimicrobial properties of chile peppers
(Capsicum species) and their uses in Mayan medicine. J. Ethnopharmacol. 52:61-70.

DeWitt, D. and P.W. Bosland. 2009. The complete chile pepper: A gardener's guide to choosing, growing, preserving, and cooking. Timber Press, Portland, OR.

DeWitt, D. and N. Gerlach. 1990. The whole chile pepper book: With over 180 hot and spicy recipes. 1st Ed. Little, Brown and Company, Boston, MA.

Elkins, R. 1997. Capsicum: Cardiovascular powerhouse and herbal catalyst. Woodland Publishing, Pleasant Grove, UT.

Eshbaugh, W.H., S.L. Guttman, and M. McLeod. 1983. The origin and evolution of domesticated Capsicum species. Ethnobiology 3:49-54.

European Cooperative for Plant Genetic Resources. 2008. ECPGR homepage: Networks: Vegetables: Solanaceae: Minimum descriptors for eggplant, Capsicum (sweet and hot pepper) and tomato. 28 Jan. 2011. <http://www.ecpgr. cgiar.org/networks/vegetables/solanaceae.html > .

Frankham, R., D.A. Birscoe, and J.D. Ballou. 2002. Introduction to conservation genetics. Cambridge University Press, New York, NY.

Gibbs, H.A.A. and L.W. O'Garro. 2004. Capsaicin content of West Indies hot pepper cultivars using colorimetric and chromatographic techniques. HortScience 39:132-135.

Hill, W.G. 1971. Design and efficiency of selection experiments for estimating genetic parameters. Biometrics 27:293-311.

Holder, R.L. 2008. Processing potential of peppers of the Capsicum genus (C. annuum L.). $\mathrm{PhD}$ thesis, The University of the West Indies, Trinidad \& Tobago.

International Plant Genetic Resources Institute, Asian Vegetable Research and Development Centre (AVRDC), and Centro Agronómico Tropical de Investigación y Enseñanza (CATIE). 1995. Descriptors for Capsicum (Capsicum spp.). IPGRI, Rome, Italy.

Jancsó, G., S. Karcsú, E. Király, A. Szebeni, L. Tóth, E. Bácsy, F. Joó, and Á. Párducz. 1984. Neurotoxin induced nerve cell degeneration: Possible involvement of calcium. Brain Res. 295:211216.

Jarret, R.L. and T. Berke. 2008. Variation for fruit morphological characteristics in a Capsicum chinense Jacq. germplasm collection. HortScience 43:1694-1697.

Johansen, D.A. 1940. Plant microtechnique. McGraw-Hill, New York, NY.
Kenny, J. 2008. The biological diversity of Trinidad and Tobago. Prospect Press, Port of Spain.

Kolatukuddy, P.E. 1984. Natural waxes on fruit. WSU Tree Fruit Research \& Extension Center. Postharvest Information Network. Washington State University, Pullman, WA. 21 Jan. 2013. $<$ http://postharvest.tfrec.wsu.edu/pages/N2I2A $>$.

Lo, Y.-C., Y.-C. Yang, I.-C. Wu, F.-C. Kuo, C.-M. Liu, H.-Wi. Wang, C.-H. Kuo, J.-Y. Wu, and D.-C. Wu. 2005. Capsaicin-induced cell death in a human gastric adenocarcinoma cell line. World J. Gastroenterol. 11:6254-6257.

Lownds, N.K., M. Banaras, and P.W. Bosland. 1993. Relationships between postharvest water loss and physical properties of pepper fruit (Capsicum annuum L.). HortScience 28: 1182-1184.

Mintz-Oron, S., T. Mandel, I. Rogachev, L. Feldberg, O. Lotan, M. Yativ, Z. Wang, R. Jetter, I. Venger, A. Adato, and A. Aharoni. 2008. Gene expression and metabolism in tomato surface tissues. Plant Physiol. 147:823-851.

Moses, M. and P. Umaharan. 2012. Genetic structure and phylogenetic relationships of Capsicum chinense. J. Amer. Soc. Hort. Sci. 137: 250-262.

Motsenbocker, C.E. 1996. Detachment force and fruit characteristics of Tabasco pepper at several stages of development. HortScience 31: 1231-1233.

Pickersgill, B. 1969. The archaeological record of chili peppers (Capsicum spp.) and the sequence of plant domestication in Peru. Amer. Antiq. 34:54-61.

Reid, B.A. 2009. Myths and realities of Caribbean history. University of Alabama Press, Tuscaloosa, AL.

Rittinger, P.A., A.R. Briggs, and D.R. Peirson. 1987. Histochemistry of lignin and suberin deposition in boundary layers formed after wounding in various plant species and organs. Can. J. Bot. 65:1886-1892.

Stewart C., Jr., M. Mazourek, G.M. Stellari, M. O'Connell, and M. Jahn. 2007. Genetic control of pungency in C. chinense via the Pun1 locus. J. Expt. Bot. 58:979-991.

Tewksbury, J.J. and G.P. Nabhan. 2001. Seed dispersal: Directed deterrence by capsaicin in chilies. Nature 412:403-404.

Walter W.M., Jr., B. Randall-Schadel, and W.E. Schadel. 1990. Wound healing in cucumber fruit. J. Amer. Soc. Hort. Sci. 115:444-452. 